\title{
HIV/AIDS knowledge among undergraduate university students: implications for health education programs in Ghana
}

\author{
${ }^{*}$ Oppong Asante $\mathrm{K}^{12}$, Oti-Boadi $\mathrm{M}^{3}$ \\ 1. School of Applied Human Sciences, College of Humanities, University of KwaZulu-Natal Durban, \\ South Africa \\ 2. Regent University College of Science and Technology, Department of Human Development and \\ Psychology, Accra, Ghana. \\ 3. Ghana Telecom University College, Tesano, Accra, Ghana
}

\begin{abstract}
Background: Globally, the spread of HIV/AIDS remains on the rise especially among adolescents who are at increased risk of infection. Sexual behavioural change remains one of the most effective ways of preventing further transmission among this vulnerable group.

Objective: To evaluate HIV/AIDS knowledge among undergraduate students' and how it can be used in HIV prevention strategies in Ghana.

Methods: A cross-sectional study was conducted using structured questionnaires among 324 conveniently selected students enrolled at a tertiary institution in Accra, Ghana.

Results: The mean age of the respondents was 23 years. Although the mean score of the participants' responses to 12 HIV/AIDS knowledge questions was 7.7 of 12 points, there was an inconsistent level of AIDS knowledge with significant gender difference. While students could identify the transmission modes and preventive measure, they were less knowledgeable about the causative agent of AIDS. Majority of the students reported having received AIDS information from both print and electronic media, but few of them received such information from parents. Although over $90 \%$ of the students knew where to access VCT services, $45 \%$ of them have not had HIV test.

Conclusion: The data underscore the urgent need for HIV/AIDS-related health education and prevention efforts targeting university students as well as younger age groups in Ghana
\end{abstract}

Keywords: HIV/AIDS, knowledge, education, students, Ghana, African Health Sciences 2013; 13(2): 270 - 277 http://dx.doi.org/10.4314/ahs.v13i2.11

\section{Introduction}

HIV/AIDS has become one of the most devastating diseases humanity has ever faced. It has become a major public health concern with about half of new infections occurring in young people ${ }^{1}$. Sub-Saharan Africa, which has just over $10 \%$ of the world's population, remains the most seriously affected region ${ }^{1}$. The impact of HIV/AIDS has caused much consternation among policy-makers as it threatens to erode socio-economic through its associated increase in morbidity and mortality of people in the productive age group ${ }^{2}$.

\begin{tabular}{|l|}
\hline *Corresponding author: \\
Kwaku Oppong Asante \\
School of Applied Human Sciences \\
College of Humanities, University of KwaZulu- \\
Natal \\
Howard College Campus \\
Durban 4041, South Africa. \\
Email: kwappong@gmail.com \\
212556250@stu.ukzn.ac.za \\
\hline
\end{tabular}

A more serious challenge today, is the growing infection rates among the adolescents in subSaharan Africa. Research has shown that the highest group found to be infected with the virus is the agegroup 15 to $24{ }^{3}$. This adolescent high-risk group accounts for 60 percent of all new infections in many countries ${ }^{4}$. Transactional sex, very common among young adults in Africa has been identified as one of the critical pathways for the transfer of the virus in Africa $^{5}$. It is not surprising that sexual intercourse has become the most predominant mode of transmission of HIV in sub-Saharan Africa, accounting for approximately $90 \%$ of all infections ${ }^{6}$.

Young people are particularly vulnerable to HIV infection because of the physical, psychological, social and economic attributes of adolescence ${ }^{7}$. Young adults are also at risk as a result of high risky sexual behaviours, attitudes, and constraints of the societies in which they grow up ${ }^{8}$. Qualitative and quantitative studies conducted in Ghana suggest that the lifestyles of university students are placing them 
at risk of contracting the HIV ${ }^{9},{ }^{10}$. Moreover peer pressure to obtain luxury items, such as expensive clothing, jewellery, fashionable hairstyles, accessories, and makeup, motivates young women to engage in transactional sex ${ }^{11-13}$.

It has also been demonstrated that increased knowledge about AIDS is not a predictor for behavioural change ${ }^{14-17}$, although knowledge about the disease is a prerequisite for change ${ }^{18}$. Knowledge of HIV and other STIs have been lacking among adolescents in Ghana, with sparse and limited literature in this area as previous studies conducted have focused on public universities ${ }^{10,19}$ with little or no data on private university students. According to the 2008 Ghana Demographic Health Survey (GDHS) $98 \%$ of women and $99 \%$ of men were aware of HIV in Ghana ${ }^{20}$. However, this has not translated into comprehensive knowledge and safe sexual behaviour as only $25 \%$ of females and $33 \%$ of males aged $15-24$ years had comprehensive knowledge of HIV ${ }^{1}$. This has health implications for propagation of the HIV/AJDS disease prevention and policy formulation.

In essence, there is a need to gather information on the basic knowledge of private university college students about HIV/AIDS, etiology, transmission, methods of prevention as well as their sexual practices since almost $45 \%$ of Ghana's population of about 24 million is aged 15 years or less ${ }^{21}$.

The main objective of this study is to evaluate HIV/AIDS knowledge among undergraduate students' and how it can be used in HIV prevention strategies in Ghana.

\section{Methods}

\section{Survey site and participants}

A cross-sectional design was adopted for the study. The participants comprised 324 university students (43.8\% females and $56.2 \%$ males) from a private tertiary institution in Accra, Ghana, with an age range of 17 to 37 . The students were enrolled in 10 different undergraduate academic programs in the participating university. Convenience sampling was used as the first author investigator is a staff in the university and easy access to students. The sample size represents $94 \%$ of response rate from eligible prospective individuals approached to take part in the study.

\section{Measures}

A well validated measure and self-administered AIDS Knowledge and Attitude Inventory ${ }^{22,23}$ were used to gather data. The instrument had questions on demographic characteristics to measure age, level, gender sex, religion, and marital status. The AIDS Knowledge and Attitude Inventory have been validated with a Ghanaian sample ${ }^{10,24}$ indicating that the instrument could be used in a Ghanaian context. Students were asked if they know their HIV status and where to get HIV testing and counseling. The following measures were used in the current study.

\section{Source of AIDS information}

Two types of information sources were assessed: media/public and personal. For media/public sources, students were asked whether they had received AIDS information in the past 6 months from any of 5 sources (e.g. internet, radio, television, magazines/newspapers and parents). Students were also asked to check sources that could provide the most reliable information on AIDS.

\section{HIV/AIDS knowledge}

Questions were asked to assess respondents' knowledge about the HIV and AIDS. There were three sets of questions assessing AIDS knowledge in different formats. The first set consisted items assessing knowledge of definition and causation of HIV/AIDS. The second set contained questions assessing modes of AIDS virus transmission, and the third set of questions regarding AIDS symptoms and preventive measures. The summation of these scores formed the basis for data analysis. The possible score ranges from 0 to 12 . Higher scores indicate more accurate knowledge on HIV/AIDS. The respondents' knowledge of HIV/AIDS was assessed by assigning a score of 1 to each correct answer of 12 yes/no HIV/AIDS related questions

\section{Survey procedure}

A list of registered students for the semester was collected from the university academic officer, who also granted the permission to conduct the survey in the university. The investigator contacted fellow faculty members from different departments in the university and asked them if they would explain the research to students and hand out the questionnaires. Most of the lecturers contacted agreed with just some few ones who declined because they were not prepared to offer the last 20 minutes of their lecture period for the purpose of this research. Having explained the nature of the research, the faculty member distributed a self-administered questionnaire to the students. The students were informed that the survey was anonymous and were assured of the confidentiality of their responses. The students were 
informed not to indicate their names on the form. Majority $(83 \%)$ of the students were in their first and second years because most of the senior faculty members who were handling the third and final year students could not administer the questionnaires.

The survey was filled out during the last 20 minutes of a 3-hour course. Participation was voluntary and students had the opportunity to refuse participation. Five (5) questionnaires were left on the desk without being filled whilst 14 students did not answer any item at all on the questionnaire. Thus, non respondents were 19(6\%). The study was approved by Human Research Committee of Regent University College of Science \& Technology.

\section{Data analysis}

The Statistical Package for the Social Sciences (SPSS) version 18.0 was used for data analysis where standard descriptive statistics were used to describe some of the findings. For the test of significance, an independent sample $t$-test and Analysis of variance (ANOVA) was used to compare the differences in mean of the knowledge on HIV/AIDS according to the various demographic characteristics In addition, Chi-square was used to explore the associations between the various variables on the sources of HIV/AIDS information.

\section{Results}

\section{Sample characteristics}

Table 1 shows the characteristics of the sample in the study. The sample consisted of [168 (52\%)] first year students, [102 (31\%)] second year students and [54(17\%)] third year students. The mean age was 22.94 years $(\mathrm{SD}=3.93)$ with $81.2 \%$ of the participants between 17 and 25 years of age. The sample consisted of $43.8 \%$ females and $56.2 \%$ males. Majority of the participants [196(60.5\%)] were single, [96 $(29.6 \%)]$ in a relationship, and the remaining [32 $(9.9 \%)]$ were married.

Table 1: Socio-demographics and differences in HIV/AIDS knowledge $(n=324)$

\begin{tabular}{llclll}
\hline Variables & $\mathbf{N}$ & $\mathbf{\%}$ & Mean (SD & Test used & $p$-value \\
\hline Gender & 182 & 56.2 & $7.52(2.21)$ & & 0.017 \\
Male & 142 & 43.8 & $8.11(2.17)$ & & \\
Female & & & & & \\
Ages & 93 & 28.7 & $7.02(2.04)$ & $6.26^{\mathrm{a}}$ & 0.0001 \\
$16-20$ & 170 & 52.5 & $8.06(2.25)$ & & \\
$21-25$ & 47 & 14.5 & $8.38(2.26)$ & & \\
$26-30$ & 14 & 4.3 & $7.29(0.99)$ & & \\
$\quad 31+$ & 196 & 60.5 & $7.47(2.25)$ & & \\
Marital status & 32 & 9.9 & $8.22(1.43)$ & & \\
Single & 96 & 29.6 & $8.25(2.43)$ & & \\
Married & & & & $2.27^{\mathrm{b}}$ & 0.203 \\
In relationship & 311 & 96.0 & $7.74(2.23)$ & & \\
Religious affiliation & & & & \\
Christian & 13 & 4.0 & $8.54(1.45)$ & & 0.257 \\
Muslims & & & & $1.37^{\mathrm{a}}$ & \\
Years in school & 168 & 52.0 & $7.80(2.22)$ & & \\
First year & 102 & 31.0 & $7.96(2.16)$ & & \\
Second year & 54 & 17.0 & $7.36(2.27)$ & & \\
Third year & & & &
\end{tabular}

a F-values from one-way ANOVA b Independent t-test Respondents' knowledge about HIV/ AIDS

\section{Meaning and causative agent of AIDS}

Virtually all the respondents [323 (99.7\%)] had heard about HIV/AIDS. The respondents' answers to the HIV/AIDS knowledge questions are shown in [table 2].The overall mean knowledge score was 7.7 out of a possible score of 12 . Majority of the respondents [304 (97.4\%)] and [320 (98.8\%)] knew the right meaning of the acronyms HIV and AIDS respectively. Surprisingly, only [177 (54.6\%)] knew that the Human Immunodeficiency Virus (HIV) causes Acquired Immunodeficiency Syndrome (AIDS).

African Health Sciences Vol 13 Issue 2 June 2013 
Table 2: Respondents' knowledge about HIV/AIDS $(n=324)$

\begin{tabular}{lll}
\hline Variables & N & \% answering correctly \\
Definitions and Symptoms & 304 & 97.4 \\
The meaning of HIV & 320 & 98.8 \\
The meaning of AIDS & 177 & 54.6 \\
HIV is the causal agent of AIDS & & \\
Modes of transmission & 156 & 50.0 \\
Unprotected sexual intercourse & 78 & 25.0 \\
Sharing of infected needles & 78 & 25.0 \\
Mother-to-child & & \\
Preventions strategies & 271 & 77.5 \\
Condom usage & 227 & 70.1 \\
Abstinence from casual sex & 202 & 62.5 \\
Avoid using infected needles & 184 & 56.8 \\
Being faithful to one sexual partner & 184 \\
\hline
\end{tabular}

\section{Modes of transmission}

Majority of the respondents [312 (96.3\%)] were able to correctly identify one or more mode of HIV of transmission with the remaining [12 (3.7\%)] not able to provide any correct answer. Out of those who correctly identified the modes of transmission, half [156 (50\%)] knew that HIV could be transmitted through unprotected sexual intercourse with infected persons; [78 $(25.0 \%)]$ by sharing needles/syringes with infected persons and the remaining [78 (25.0\%)] through mother- to child medium.

\section{Preventive measures}

Most of the respondents [306 (94.4\%)] were knowledgeable about the various ways of preventing HIV infection. The four commonly identified means of preventing HIV infection were: condom usage [271(77.5\%)], abstinence from casual sex, [227(70.1\%)], avoiding sharing of sharp objects [202(62.5\%)] and being faithful to a partner [184(56.8\%)]. Additionally, majority of the participants [288 (88.9\%)] know that there is no cure for AIDS, and that one cannot always say if someone is infected with the virus [265 (81.8\%)].

For the test of significance, an independent sample $t$-test and Analysis of variance (ANOVA) was used to compare the differences in mean of the knowledge on HIV/AIDS according to the various demographic characteristics are also presented in table I. The results of an independent sample $t$-test which compared the differences in the mean knowledge on HIV/AIDS according to gender and religious affiliation indicated that female students $(M$ $=8.11, \mathrm{SD}=2.17)$ had more knowledge about $\mathrm{HIV} / \mathrm{AIDS}$ than their males $(M=7.5, S D=2.21)$ counterpart $[t(322)=2.40, p=0.017]$. Although Muslim students scored higher on HIV/AIDS knowledge $(M=8.54, S D=1.45)$, than Christian students $(M=7.74, S D=2.23)$, this difference was not strong enough to yield statistical significance $[t$ $(322)=2.27, p=0.0 .203]$. The One-Way Analysis of variance (ANOVA) indicated that there was a statistically significant difference in the HIV/AIDS Knowledge scores for the four age groups [F (3, $321)=6.26, p=0.0001]$. Post-hoc test comparisons using the Turkey HSD test indicated that the mean scores the $16-20$ years group $(M=7.02, S D=$ 2.04) was significantly different from both the $21-$ 25 years group $(M=8.06, S D=2.25)$ and the $26-$ 30 years group $(M=8.38, S D=2.26)$. The $31+$ years group did not differ significantly with any of the age groups.

The ANOVA results also indicated a statistically significant difference in the HIV/AIDS knowledge scores for the marital status of the participants [F (3, $321)=4.86, p=0.008]$. Post-hoc test comparisons using the Turkey HSD test indicated that the mean scores for student who were single $(M=7.47, S D$ $=2.25)$ was significantly different from those who were "in relationships" $(M=8.25, S D=2.43)$. Students who were married $(M=8.22, S D=1.43)$ did not differ significantly from either single or students in relationship.

\section{Sources of HIV/AIDS information}

As shown in table 3, approximately $82.7 \%$ of the sample reported having received information about HIV/AIDS from the television, 63\% from the internet, $53.4 \%$ from radio, whiles newspapers/ 
magazines and parents accounted for $43.5 \%$ and $26.9 \%$, respectively. The chi-square $\left(\chi^{2}\right)$ analysis was used to examine the relationship between marital status, age-groups and year in school and the five sources of information. Only two, out of the 5 sources of HIV/AIDS information differed significantly between the number of years in school and their marital status. Compared with third year students, more first and second year students had received information about AIDS through the internet $(49.2 \%, 39.2$, and $11.7 \%)$ for first, second and third year students respectively $\left[\chi^{2}(2, \mathrm{~N}=324)\right.$ $=6.70, p=.03]$. With regard to seeking information from television, more single students identified television as their preferred choice of information about AIDS (63.4\%, 26.0\%) and 9.7\%) for single, "in relationship", and married students respectively $\left[\chi^{2}(2, \mathrm{~N}=324)=6.23, p=.04\right]$.

Table 3: Sources from which students (\%) received HIV/AIDS information in the previous 6 months

\begin{tabular}{|c|c|c|c|c|c|c|c|c|c|}
\hline \multirow[t]{2}{*}{ Sources } & \multirow{2}{*}{$\begin{array}{l}\text { Overall } \\
\text { number }\end{array}$} & \multirow{2}{*}{$\begin{array}{l}\text { Sex } \\
\text { Male }\end{array}$} & \multirow{2}{*}{ Female } & \multicolumn{2}{|c|}{ Year in School } & \multicolumn{3}{|c|}{ Marital Status } & \multirow[b]{2}{*}{ Married } \\
\hline & & & & First & Second & Third & Single & $\begin{array}{l}\text { In rela- } \\
\text { tionship }\end{array}$ & \\
\hline Television & 83 & 84 & 82 & 85 & 79 & 85 & 81 & $87 *$ & 75 \\
\hline Internet & 63 & 36 & 39 & $35^{*}$ & 46 & 26 & 39 & 38 & 25 \\
\hline Radio & 53 & 53 & 54 & 53 & 59 & 44 & 55 & 50 & 53 \\
\hline Newspapers & 44 & 41 & 47 & 43 & 47 & 39 & 43 & 44 & 44 \\
\hline Parents & 27 & 27 & 26 & 27 & 29 & 20 & 29 & 23 & 25 \\
\hline
\end{tabular}

$* \mathrm{p}<.05$

\section{Counseling and testing}

Over $90 \%$ of the students reported to know where to have an HIV test, while $45 \%$ have had an HIV test. More male students $(67 \%)$ indicated they would offer themselves for a test in the future as compared to only $38.8 \%$ of their female counterparts.

\section{Discussion}

The data in the present study indicated an inconsistent level of HIV knowledge among undergraduate students in Ghana. Over $90 \%$ of the students have heard about HIV/AIDS. While students could identify the various modes of HIV transmission and preventive measures, they were less knowledgeable about the causative agent of AIDS.

The result also revealed a significant gender differences in HIV knowledge among university students in Ghana, with females more knowledgeable than males. This finding is consistent with studies conducted in Nigeria ${ }^{25,26}$ which found that AIDS knowledge differs on the basis of gender among university students. However, ${ }^{27}$ had indicated no gender differences on HIV knowledge and attitudes among university students in Nigeria.

The data suggest that majority of students receive HIV/AIDS information from both print and electronic media (e.g. television, internet, radio, newspaper/magazines) but few had received same from their parents. Consistent with findings in Ghana ${ }^{28}$, Nigeria ${ }^{29,30}$ and other countries ${ }^{31,32}$, university students in Ghana appear to rely on both print and electronic media as the major source of HIV/AIDS information. Mass-media campaigns utilizing television radio, posters and billboards have been shown to be more effective for addressing specific issues $^{33}$. They have also been proven to be effective in increasing knowledge, improving self-efficacy to use condoms, influencing social norms, increasing the amount of interpersonal communication and raising awareness of health services ${ }^{33}$. These media therefore have an important role to play in raising AIDS awareness among young adults including university students.

Discussion of sexual issues between parents and their children are rare in Ghana due to the fact that the Ghanaian culture has a more conservative, religious and traditional beliefs on issues of sexuality, condom usage and marriage ${ }^{34}$. It is also possible that the older generation had not received any information on sex education, making it difficult for them to approach the issue as parents themselves. Furthermore, residential pattern and family structure might reduce the opportunity to discuss sensitive topics like sex. Parents should discuss reproductive sexual issues with their children and young adults, because a strong adult protective shield for young 
people has been shown to decrease their risk of HIV infection ${ }^{35}$.

Another interesting finding of the study is that over $90 \%$ of the students reported not to have had HIV test, although over $45 \%$ of them knew where to access Counseling and Testing services. This finding is consistent with the studies of ${ }^{10,19}$ that indicated that majority of public university students had not taken the HIV test. The unwillingness of students to take HIV test could be attributed to fear, anxiety and stigma and discrimination associated with the Counseling and Testing and AIDS respectively. The fact that over $90 \%$ of the participants are single and "in relationship" raises a lot of health issues as only $33 \%$ and $67 \%$ of females and males students respectively indicated they would offer themselves for a test in the future.

\section{Implication for intervention and policy}

The present study showed that university students in a tertiary institution in Ghana were knowledgeable about HIV/AIDS, used both print and electronic media (especially television and the internet) as their sources to HIV information, and majority of them have not had HIV test, although some know about the availability of Counseling and Testing services. There is however, the need to embark on extensive and sustained HIV/AIDS educational programs. The following recommendations should be taken into consideration when developing an effective education strategy:

A strong collaboration among universities, polytechnic, colleges of education and Ministry of Health should be built to help in the design and implementation of comprehensive special education to curtail the spread of HIV/AIDS in Ghana. Such programs should begin at the primary school levels and extending beyond formal education to reach parents and other adults in the larger community. The existing of HIV/AIDS Clubs in some tertiary institutions in Ghana should be scaled up to cover all higher and tertiary institutions.

Parents, teachers and sex educators should be more involved in HIV/AIDS education and prevention strategies. Parents for instance, should be encouraged to discuss sexual reproductive health issues such as condom usage and abstinence with their children. Availability of condoms is definitely important but individuals need to have confidence and firm belief that they can actually use it for effective intervention programs.

The use of the internet for the dissemination of HIV/AIDS information should be intensified African Health Sciences Vol 13 Issue 2 June 2013 since most of the youth as indicated in this study used that medium. The Ghana AIDS Commission should encourage its development partners (Non Governmental Organizations, Community Based Organizations, etc.) to provide up to date health related HIV information on their websites.

This study was the first of its kind to be conducted among private university students in a Ghanaian context. This study therefore fills a gap in research with respect to HIV/AIDS knowledge among private university students in a Ghanaian context.

\section{Study limitations}

The data analyses were done based on a cross sectional data; therefore, causal interpretation of the results cannot be established. The results cannot be generalized to the entire population of undergraduate students in Ghana due to the relative sample size and the non-probability sampling technique used. In addition to this, since all variables were measured by self-report instruments, which may have caused some bias considering the sensitive nature of the HIV/ AIDS as young people may be reluctant to provide information about their sexual activity and may have tended toward more socially acceptable responses. It is important for future studies also to use other forms of data collection, such as interviews, and focus group discussions. Future studies should assess student's risky sexual behaviour and attitudes towards people living with HIV, to help provide a comprehensive understanding of sexual issues among university students.

\section{Conclusion}

The present study showed that university students in a tertiary institution in Ghana are knowledgeable about HIV/AIDS, used both print and electronic media (especially television and the internet) as their sources of HIV information, and majority of them have not had HIV test, although some know about the availability of Counseling and Testing services. The few numbers of students willing to have HIV test in the future should be of great concern to public health practitioners. Further extensive studies that will explore the reasons for their intensions for not willing to have HIV test are recommended.

\section{References}

1. UNAIDS.UNAIDS Report on the global HIV/ AIDS epidemic update, 2010. Geneva: Switzerland. 
Retrieved from http://www.unaids.org/en/ regionscountries/countries/ghana/.

2. Barnett T, Whitehead A. HIV/AIDS in Africa: Implications for "development" and major policy implications. Fourth SCUSA Inter-University Colloquim. University of East Anglia, Norwich, 5-8th September 1997.

3. UNICEF, UNAIDS, WHO .Young People and HIV/AIDS, Opportunity in Crisis. From http:// www.unicef.org/pubsgen/youngpeople-hivaids/ youngpeople-hivaids.pdf Working Paper No. 52. Washington, DC: PSI Research Division, 2002.

4. World Bank .HIV/AIDS prevention and Care Strategies for HIV. Retrieved fromwww.worldbank.org 2002.

5. Cote A, Sobela F, Dzokoto A, Nzambi K, Asamoah Adu C, Labbe A, et al. 'Transactional sex is the driving force in the dynamics of HIV in Accra, Ghana.' AIDS 2004; 18: 917-925.

6. De Kock KM, Ekpini E, Gnaore E. The public health implications of AIDS research in Africa. Journal of the American Medical Association 1994; 6: 481-486.

7. Earl D. Re-examination of the paradigm of HIV risk reduction in Adolescents. Journal of the American Osteopathic Association 1995; 95(12): 725728.

8. Population Reference Bureau. Improving the Reproductive Health of Sub-Sabaran Africa's Youth. Washington, DC: The Bureau, 2006.

9. Anarfi J. Universities and HIV/AIDS in Sub Saharan Africa: A Case Study of the University of Ghana, Legon. Paper prepared for ADEA Working Group in Higher Education. Accra, Ghana, 2000.

10. Tagoe M, Aggor RA. Knowledge, behaviour, perceptions and attitudes of university of Ghana students towards HIV/AIDS: what does behavioural surveillance survey tell us? Journal of Health and Human Services Administration 2009; 32(1): 51-84.

11. Ankomah A. Condom use in sexual exchange relationships among young single adults in Ghana. AIDS Education and Prevention 1998; 10: 303-316.

12. Longfield K, Glick A, Waithaka M, Berman J. 'Cross-Generational Relationships in Kenya: Couples' Motivations, Risk Perception for STIs/HIV and Condom Use." Working Paper No. 52. Washington, DC: PSI Research Division, 2002.

13. Temin MJ, Okonofua FE, Omorodion FO, Renne EP, Coplan P. Perception of sexual behaviour and knowledge about sexually transmitted disease among adolescents in Benin City, Nigeria. International Family Planning Perspective 1999; 25(4): 186-190.

14. Onah HE, Mbah AU, Chukwuka JC, Ikeme AC. HIV/AIDS awareness and sexual practices among undergraduates in Enugu, Nigeria. Nigerian Postgraduate Medical Journal 2004; 11(2): 121-125.

15. Keller SE, Bartlett JA, Schleifer A, Johnson RL, Pinner E, Delaney B. HIV relevant sexual behavior among a healthy inner city heterosexual adolescent population in an endemic area of HIV. Journal of Adolescent Health Care 1991; 12: 44-48.

16. Diclemente RJ. Predictors of HIV-preventive sexual behavior in a high-risk adolescent population: the influence of perceived peer norms and sexual communication on incarcerated adolescents' consistent use of condoms. Journal of Adolescent Health 1991 12(5), 385-390

17. Hingson R, Strunin L, Berlin B. Acquired immunodeficiency syndrome transmission: Changes in knowledge and behaviours among teenagers. Massachusetts Statewide Surveys, 1986 to 1988. Pediatrics $1990 ; 85: 24-29$.

18. Fawole IO, Asuzu MC, Oduntan SO, Brieger WR. A school based AIDS education programme for secondary school students in Nigeria: A review of effectiveness. Health Education Research Theory and Practice 1999; 14(5): 675-683.

19. Gordon M, Inusah F. Attitude and perception of University Students on Voluntary HIV Testing: A Case of the University of Ghana. Unpublished Bachelor of Science Long Essay. School of Nursing, University of Ghana, 2003.

20. Ghana Statistical Service. Ghana demographic and bealth survey, 2008. Accra, Ghana: GSS, GHS, ICF and Macro, 2009

21. Ghana Statistical Service. The 2010 Population and Housing Census Provisional Results. Ghana Statistical Service. Retrieved from http:// www.ghana.gov.gh/census/phc2010.pdf, 2011

22. Koopman C, Rotheram-Boru, M, Henderso R, Bradley J, Hunter T. Assessment of knowledge about AIDS and beliefs about AIDS prevention among adolescents. AIDS Education and Prevention 1990 2(1): 58-69.

23. Shrum JC, Turner NH, Bruce KEM. Development of an instrument to measure attitudes toward acquired immune deficiency syndrome. AIDS Education and Prevention 1989; 1: 222-230.

24. Ulasi CI, Preko PO, Baidoo JA, Bayard B, Ehiri JE, Jolly CM, et al. (2009). HIV/AIDS-related 
stigma in Kumasi, Ghana. Health and Place 2009; 15(1): 255-262.

25. Aluede O, Imhonde H, Maliki A, Alutu A. Assessing Nigerian University Students' Knowledge about HIV/AIDS. Journal of Social Science 2005; 11: 207-213.

26. Chng L, Eke-Huber E, Eaddy S, Collins J. Nigerian College Students: HIV Knowledge, Perceived Susceptibility for HIV and Sexual Behaviours. College Student Journal 2005; 39(1): 6071.

27. Durojaiye OC. Knowledge, attitude and practice of HIV/AIDS: Behavior change among tertiary education students in Lagos, Nigeria. Annals of Tropical Medicine and Public Health 2011; 4: 18-24

28. Sallar AM. Correlates of Misperceptions in HIV knowledge and attitude towards people living with HIV/AIDS (PLWHAs) among in-school and out of- school adolescents in Ghana. African Health Sciences 2009; 9: 82-91.

29. Oyo-Ita AE, Ikpeme BM, Etokidem AJ, Offor JB, Okokon EO, Etuk SJ. Knowledge of HIV/ AIDS among secondary school adolescents in Calabar-Nigeria. Annals of African Medicine 2005, 4(1), 2-6.

30. Nwokoji UA, Ajuwon AJ. Knowledge of AIDS and HIV risk related sexual behavior among
Nigerian naval personnel. BMC Public Health 2004; 4:24

31. Ungan M, Yaman H. AIDS knowledge and educational needs of technical university students in Turkey. Patient Education Counseling 2003; 51: 163167

32. Li X, Lin C, Gao Z, Staton B, Fang X, Yin Q., et al. HIV/AIDS knowledge and the implications for health promotion programs among Chinese college students: geographic, gender and age differences. Health Promotion International 2004; 19 (3): 345-356.

33. Abdool Karim Q, Meyer-Weitz, Harrison A. Interventions with youth in high prevalence areas. In Mayer KH, Pizer HF, editors. HIV preventions: A comprehensive approach. London: Academic Press; 2009.

34. Asante KO, Doku PN. Cultural adaptation of the condom use self-efficacy scale (CUSES) in Ghana. BMC Public Health 2010; 10: 227-233.

35. Petersen I, Bhana A, McKay M. Sexual violence and youth in South Africa: The need for community-based prevention interventions. Child Abuse Neglect 2005; 29: 1233 - 1248. 